\title{
University of Montana
}

ScholarWorks at University of Montana

Numerical Terradynamic Simulation Group

Publications

Numerical Terradynamic Simulation Group

$12-1988$

\section{Rapid Estimation of Coniferous Forest Leaf Area Index Using a Portable Integrating Radiometer}

Lars Lowell Pierce

The University of Montana

Steven W. Running

University of Montana - Missoula

Let us know how access to this document benefits you.

Follow this and additional works at: https://scholarworks.umt.edu/ntsg_pubs

\section{Recommended Citation}

Pierce, L. L. and Running, S. W. (1988), Rapid Estimation of Coniferous Forest Leaf Area Index Using a Portable Integrating Radiometer. Ecology, 69: 1762-1767. doi:10.2307/1941154

This Article is brought to you for free and open access by the Numerical Terradynamic Simulation Group at ScholarWorks at University of Montana. It has been accepted for inclusion in Numerical Terradynamic Simulation Group Publications by an authorized administrator of ScholarWorks at

University of Montana. For more information, please contact scholarworks@mso.umt.edu. 


\title{
RAPID ESTIMATION OF CONIFEROUS FOREST LEAF AREA INDEX USING A PORTABLE INTEGRATING RADIOMETER ${ }^{1}$
}

\author{
Lars L. Pierce and Steven W. RunNing \\ School of Forestry, University of Montana, Missoula, Montana 59812 USA
}

\begin{abstract}
Canopy transmittance was measured at 1200 and 1400 local solar time using an integrating radiometer on seven coniferous forest stands in western Montana, ranging in projected leaf area index (LAI) from $1.7-5.3 \mathrm{~m}^{2} / \mathrm{m}^{2}$. Transmittance of each 1-ha stand was measured at 96,000 points, yet measurement required $<1 \mathrm{~h}$ because the instrument instantaneously integrates 80 radiometer measurements at once. The Beer-Lambert Law was inverted to estimate LAI using measured transmittance and an extinction coefficient of 0.52 . LAI estimated by transmittance was highly correlated with LAI measured by sapwood-based allometric equations at both the $1200\left(R^{2}=0.97\right)$ and $1400\left(R^{2}=0.94\right)$ measurement times. The results suggest that the technique has a wide applicability given the range of LAIs, stand densities (450-4140 trees/ha) and illumination angles $\left(32^{\circ}-57^{\circ}\right)$ under which it was tested.
\end{abstract}

Key words: Beer-Lambert Law; canopy transmittance; coniferous forest; extinction coefficient; leaf area index.

\section{INTRODUCTION}

Leaf area index (LAI, projected leaf area per unit ground area) is an important structural property of forests. Because leaf surfaces are the primary sites of energy and mass exchange, important processes such as canopy interception, transpiration, and net photosynthesis are directly proportional to LAI. McNaughton and Jarvis (1983) demonstrated that LAI is important in determining canopy-scale estimates of evapotranspiration. Grier and Running (1977) and Gholz (1982) related LAI to the site water balance of mature coniferous forest communities in western Oregon $\left(R^{2}=0.95-0.99\right)$. Functional relationships also exist between LAI and net primary production $\left(R^{2}=\right.$ 0.96; Gholz 1982) and stemwood production $\left(R^{2}=\right.$ 0.96; Schroeder et al. 1982) of temperate coniferous forests. McLeod and Running (1988) correlated LAI to volume growth $\left(R^{2}=0.93\right)$ of ponderosa pine (Pinus ponderos $a$ ) stands in western Montana. Several recent reports (Wittwer 1983, Botkin 1986) have identified LAI as the single most important variable for characterizing vegetation energy and mass exchange for global scale research.

Marshall and Waring (1986) compared four methods of determining leaf area index for conifer stands. They found that stand LAI was best estimated using either: (1) litterfall, (2) allometric equations relating sapwood basal area to leaf area, or (3) measurements of canopy transmittance. Litterfall techniques, however, require measurement of foliage turnover rates, which are highly variable and assume that the stand has reached equilibrium leaf area.

\footnotetext{
${ }^{1}$ Manuscript received 4 January 1988; revised and accepted 30 April 1988.
}

Strong relationships have been shown between LAI and sapwood basal area (Snell and Brown 1978, Schroeder et al. 1982, Waring et al. 1982, Marshall and Waring 1986, Hungerford 1987, McLeod and Running 1988). However, Hungerford (1987) also showed that sapwood area : leaf area ratios change with geographic location and stand density, which implies that allometric relations may not necessarily be universally applied. These allometric equations are difficult and time consuming to build in new regions because of the destructive sampling and measurement required.

Sampling of canopy transmittance to estimate LAI is an alternative to litterfall and sapwood area : leaf area allometric relations. Lang (1987) found that measurements of canopy transmittance provided a practical method for determining LAI of Monterey pine (Pinus radiata) stands. When canopy transmittance is integrated throughout a 24-h period, estimates of standlevel LAI can be obtained using relatively few point measurements. Estimates of canopy transmittance can be improved through the use of mobile sensors (Pech 1986). However, current instruments and techniques do not provide timely or cost-effective ways to obtain this information over larger areas associated with the minimum resolution of some satellite imagery, as large as $1 \mathrm{~km}^{2}$. A technique is required that would allow for rapid estimation of LAI at the stand level so that a large number of stand-level estimates of LAI could be collected in a relatively short time.

The "Sunfleck Ceptometer" (model SF-80, Decagon Devices, Incorporated), is a hand-held device designed to measure instantaneous fluxes of photosynthetically active radiation (PAR, $400-700 \mathrm{~nm}$ ) quickly and easily. The ceptometer has 80 light sensors placed at $1-\mathrm{cm}$ intervals along a linear $80-\mathrm{cm}$ wand, attached to a bat- 
TABLE 1. Biometric characteristics of the seven stands measured.

\begin{tabular}{|c|c|c|c|c|c|}
\hline \multirow[b]{2}{*}{ Stand } & \multirow[b]{2}{*}{ Dominant species } & \multirow{2}{*}{$\begin{array}{c}\begin{array}{c}\text { Basal area } \\
\left(\mathrm{m}^{2} / \mathrm{ha}\right)\end{array} \\
\bar{X}(\mathrm{SD})\end{array}$} & \multirow{2}{*}{$\begin{array}{c}\text { Trees/ha } \\
\bar{X}(\mathrm{SD})\end{array}$} & \multirow{2}{*}{$\begin{array}{c}\begin{array}{c}\text { Projected LAI } \\
\left(\mathrm{m}^{2} / \mathrm{m}^{2}\right)\end{array} \\
\bar{X}(\mathrm{sD})\end{array}$} & \multirow{2}{*}{$\begin{array}{l}\text { Allometric } \\
\text { reference* }\end{array}$} \\
\hline & & & & & \\
\hline Ninemile & Pinus ponderosa & $30.3(11.4)$ & $720(392)$ & $1.7(0.5)$ & 1 \\
\hline Plains & $P$. ponderosa & $42.5(4.6)$ & $900(418)$ & $2.4(0.2)$ & 1 \\
\hline Sorrel & P. ponderosa & $49.4(5.9)$ & $570(141)$ & $2.6(0.4)$ & 1 \\
\hline Noxon & $P$. ponderosa & $50.0(6.0)$ & $450(103)$ & $3.3(0.6)$ & 1 \\
\hline Lubrecht & $P$. contorta & $51.4(8.4)$ & $4140(1892)$ & $4.0(0.5)$ & 2 \\
\hline Rainy Lake & Picea engelmannii & $34.1(10.1)$ & $480(311)$ & $4.1(1.6)$ & 3 \\
\hline Yew Creek & Abies grandis & $49.6(7.9)$ & $1010(636)$ & $5.3(1.2)$ & 4 \\
\hline
\end{tabular}

*1: McLeod and Running 1988; 2: Hungerford 1987; 3: Waring et al. 1982; 4: Snell and Brown 1978.

tery-powered digital data logger. A microprocessor scans the 80 light sensors on demand and calculates the arithmetic average (Decagon Devices 1987). This value can then be stored in the device memory or several more measurements can be taken prior to calculating an average for a given sample point, allowing the user to move rapidly through a stand while collecting a large number of point samples.

Three basic objectives were defined for this study; first, to determine if the transmittance measurements obtained with the ceptometer provide accurate estimates of stand LAI; second, to analyze how differing LAI, stand structure, and sun angles affect accuracy; and third, to determine the extent to which this technique is limited by sampling error.

\section{MethodS}

LAI was measured on seven conifer stands in western Montana by converting measurements of sapwood basal area to projected LAI using allometric-based prediction equations (Table 1). Projected leaf area is defined as the "receiving area for beam radiation with the sun at zenith" (Lee 1978). Stands of 1 ha in size were chosen to cover the range of LAI typical of healthy stands in western Montana as well as to test the technique under a variety of stand structures and species compositions.

McLeod and Running (1988), using destructive sampling techniques, developed sapwood area : leaf area allometric equations for the stands at Sorrel, Plains, and Noxon (Table 1). In each stand, six $40 \mathrm{~m}^{2}$ fixedsize plots were established and species, height, and diameter at $1.37 \mathrm{~m}$ above ground were recorded for each tree within the plot. Bark and sapwood thickness were averaged from two increment cores also taken from each tree at $1.37 \mathrm{~m}$ above ground. Sapwood basal area was calculated by subtracting the heartwood basal area from total inside-the-bark basal area. Plot LAI was then determined by applying the prediction equation to each tree (Table 1), summing the individual tree leaf areas, and dividing by the area of the plot. Stand LAI is based on an arithmetic average of these six plots.

The LAI of Ninemile, Lubrecht, Rainy Lake, and
Yew Creek stands was determined by measurement of sapwood basal area of individual trees within five variable-radius plots randomly located in each stand. In order to determine if fixed-size plots produced different estimates of plet LAI than did variable-radius plots, 20 separate plots with identical center points were measured using both techniques. A paired difference $t$ test conducted on the plot means yielded no significant difference between the two techniques $(P=.05)$. Sapwood and bark thickness at $1.37 \mathrm{~m}$ above the ground was measured with an increment core taken from the side of the tree facing the plot center (Marshall and Waring 1986). Species and tree diameter were also recorded. Sapwood area was again determined by subtracting the bark and heartwood area from the tree basal area. Plot LAI was calculated as above, and stand LAI is the arithmetic average of the five variable-radius plots.

Canopy transmittance of each stand was sampled using the sunfleck ceptometer on seven cloudless days between 9 and 22 September 1987 at 1200 and 1400 local solar time. The two measurement times provided two different sun angles under which to test this technique. Transmittance under the canopy was sampled along a systematically gridded transect whose starting point was randomly located. Each transect contained 60 sample stops, spaced $\approx 6 \mathrm{~m}$ apart. Stops were located by pacing the required distance along the transect. At each stop, 20 measurements of PAR were taken while holding the ceptometer level $\left( \pm 2^{\circ}\right)$ in outstretched arms and turning a $360^{\circ}$ circle in $15^{\circ}$ increments. The 20 measurements were then averaged and stored in memory. The effective sample area at each stop using this technique is $\approx 9 \mathrm{~m}^{2}$, represented by 1600 point measurements of PAR, and was sampled in $<30$ s. The total transect took $<45 \mathrm{~min}$ to complete, yet represents 96000 point samples of incoming PAR per stand. Total incoming PAR was measured, as a minimum, at the beginning and end of each transect in a nearby clearcut or road. Additional measurements of total incoming PAR were made during sampling where permitted by large $\left(>250 \mathrm{~m}^{2}\right)$ canopy openings. In all cases, diffuse PAR was $\approx 7-10 \%$ of total PAR.

Data were downloaded from the ceptometer to an 
TABLE 2. The calculated extinction coefficients and effective incidence angles for each stand. Extinction coefficients $(K)$ were calculated using the equation $K=-\ln \left(Q_{t} / \mathrm{Q}_{0}\right) / \mathrm{LAI}$ where LAI was previously measured by allometric equations. Effective incidence angle is an integrated measure of slope, aspect, and sun angle.

\begin{tabular}{|c|c|c|c|c|c|c|}
\hline \multirow[b]{2}{*}{ Stand } & \multicolumn{2}{|c|}{ Extinction coefficient } & \multirow[b]{2}{*}{ \% Slope } & \multirow[b]{2}{*}{ Aspect } & \multicolumn{2}{|c|}{ Effective incidence angle } \\
\hline & 1200 & 1400 & & & 1200 & 1400 \\
\hline Ninemile & 0.53 & 0.54 & 0 & flat & $32^{\circ}$ & $34^{\circ}$ \\
\hline Plains & 0.49 & 0.43 & 0 & flat & $46^{\circ}$ & $53^{\circ}$ \\
\hline Sorrel & 0.51 & 0.54 & 10 & $190^{\circ}$ & $37^{\circ}$ & $46^{\circ}$ \\
\hline Noxon & 0.48 & 0.56 & 20 & $180^{\circ}$ & $43^{\circ}$ & $51^{\circ}$ \\
\hline Lubrecht & 0.48 & 0.49 & 18 & $250^{\circ}$ & $44^{\circ}$ & $57^{\circ}$ \\
\hline Rainy Lake & 0.52 & 0.61 & 0 & flat & $44^{\circ}$ & $51^{\circ}$ \\
\hline Yew Creek & 0.58 & 0.53 & 25 & $130^{\circ}$ & $40^{\circ}$ & $41^{\circ}$ \\
\hline Range & $0.48-0.58$ & $0.43-0.61$ & & & $32^{\circ}-46^{\circ}$ & $34^{\circ}-57^{\circ}$ \\
\hline Mean & 0.51 & 0.53 & & & & \\
\hline
\end{tabular}

IBM PC/XT. The memory chip within the ceptometer will hold $\approx 1000$ entries, each of which includes time, sunfleck percentage, and PAR in millimoles per square metre per second (Decagon Devices 1987). Canopy transmittance $\left(Q_{l} / Q_{0}\right)$ for each transect was calculated by dividing the average below-canopy $\operatorname{PAR}\left(Q_{i}\right)$ by average total incoming PAR $\left(Q_{0}\right)$. Transects that contained multiple measurements of $Q_{0}$ were broken into sections bounded by individual measurements of $Q_{0}$. Canopy transmittance of each section was calculated as above, weighted according to the number of contributing $Q_{i}$ samples, and summed to determine average canopy transmittance for the stand.

The average canopy transmittance for each stand at 1200 and 1400 local solar time was converted to LAI using the Beer-Lambert Law:

$$
\mathrm{LAI}=-\ln \left(Q_{i} / Q_{0}\right) / K,
$$

where LAI = projected LAI and $K=$ light extinction coefficient. If $Q_{i} / Q_{0}$ is considered as a single variable, then all variables in Eq. 1 are unitless. The extinction coefficient is difficult to calculate independent of LAI because it is a function of sun angle, leaf orientation, and amount of stem and branch material. Therefore, we assumed $K=0.52$ because this is the midpoint in the range of extinction coefficients reported for conifer canopies (0.40-0.65, Jarvis and Leverenz 1983).

The Beer-Lambert Law assumes that leaf inclination angles are spherically and randomly distributed and that the foliage is distributed randomly in space (Jarvis and Leverenz 1983). These assumptions imply that leaf area index normal to a beam of radiation is independent of the angle at which the radiation strikes the canopy (Landsberg 1986). Norman and Jarvis (1975) showed that even in canopies with a nonrandom distribution of foliage, such as Sitka spruce (Picea sitchensis), the assumption of random leaf distribution did not produce large errors in the estimate of LAI. Caldwell et al. (1986) found that a model which accounts for nonrandom azimuth foliage distribution in Quercus coccifera did not significantly improve estimates of in- tercepted PAR over a model which assumes a random azimuth foliage distribution.

To determine how LAI and stand structure affect the accuracy of this technique, we calculated the estimation error $(e)$ as a proportion of LAI using Eq. 2:

$$
e^{2}=\left[t^{2} \cdot(\mathrm{CV})^{2}\right] / n,
$$

where $n=$ number of samples, $t=t$ value given $n$ and a confidence level of $95 \%$, and $\mathrm{cv}=$ coefficient of variation in stop-to-stop, ceptometer-based estimates of LAI. Given the coefficient of variation for each stand, the estimation error was calculated in increments of 10 samples over the range $n=10-60$ samples. Each ceptometer sample is an average of 1600 point samples, making comparison with individual point radiometers impossible.

To assess the effects of sampling error on the applicability of this technique across a range of LAI, transmittance was repeatedly measured 10 times under three uniform light sources representing full sunlight and attenuated sunlight for LAI $=2.7$ and $\mathrm{LAI}=4.7$. The standard deviation between the 10 repetitions was calculated for each light source. Given that $95 \%$ of all measurements of transmittance for a uniform light source will fall within two standard deviations of the mean, we calculated a mean, maximum, and minimum transmittance for a range of LAI from 1 to 8 . Using the Beer-Lambert Law (assuming $K=0.52$ ), the measurements of transmittance were converted to a mean, minimum, and maximum LAI. The range of variation was described as a percentage of LAI, so that at any given sample point, one could determine the amount of error the sampling technique would contribute to an estimate of LAI.

\section{RESULTS AND DISCUSSION}

To test our assumption of $K=0.52$, we inverted Eq. 1 and calculated the extinction coefficients for each stand given measured LAI and transmittance at 1200 and 1400 (Table 2). Averaging all of these 14 extinction coefficients together produced a value of $K=0.52$, 
supporting our assumption that 0.52 is an appropriate average extinction coefficient for conifer canopies.

To test the assumption that LAI normal to a beam of radiation is independent of sun angle, we performed a paired difference $t$ test between the seven extinction coefficients calculated at 1200 and the seven calculated at 1400 . This test showed $(t$ statistic $=0.721)$ that there is no significant difference between the 1200 and 1400 extinction coefficients $(P=.05)$. In addition, a regression analysis between the change in extinction coefficient and the change in effective incidence angle was nonsignificant. These results support our assumption that extinction coefficients and canopy transmittance are independent of effective incidence angle for the range of sun angles and stand structures we tested.

Measured canopy transmittance at 1200 and 1400 was plotted against measured LAI for each stand (Fig. 1). Given the validity of the Beer-Lambert Law assumptions, we transposed Eq. 1 to predict transmittance for each stand based on measured LAI and $K=$ 0.52 and plotted it as the curve through the data points in Fig. 1. A regression analysis between expected and measured transmittance shows a strong relationship for both the $1200\left(R^{2}=0.99\right.$, SEE [standard error of the estimate $]=0.047)$ and $1400\left(R^{2}=0.94\right.$, SEE $\left.=0.115\right)$ data, suggesting that the ceptometer can accurately measure canopy transmittance for these conditions and the Beer-Lambert Law assumptions are adequate.

To determine if the measurements of transmittance obtained using the ceptometer could be used to predict LAI, we regressed measured LAI against LAI predicted using the Beer-Lambert Law given measured transmittance and $K=0.52$ (Fig. 2). The error bars with each point in Fig. 2 represent one standard error of mean predicted LAI. At both the $1200\left(R^{2}=0.97\right)$ and $1400\left(R^{2}=0.94\right)$ effective incidence angles, predicted LAI is strongly correlated with measured LAI, sug-

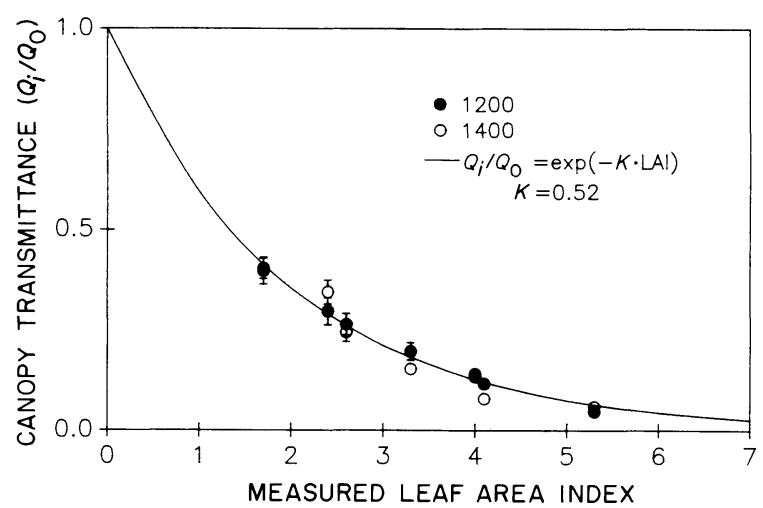

FIG. 1. The relationship between stand projected LAI and canopy transmittance $\left(Q_{i} / Q_{0}\right)$ measured at $1200\left(R^{2}=0.99\right)$ and $1400\left(R^{2}=0.94\right)$ local solar time using the sunfleck ceptometer. The Beer-Lambert Law defines the curve passing through the data points. The error bars represent \pm 1 standard error of the mean transmittance.

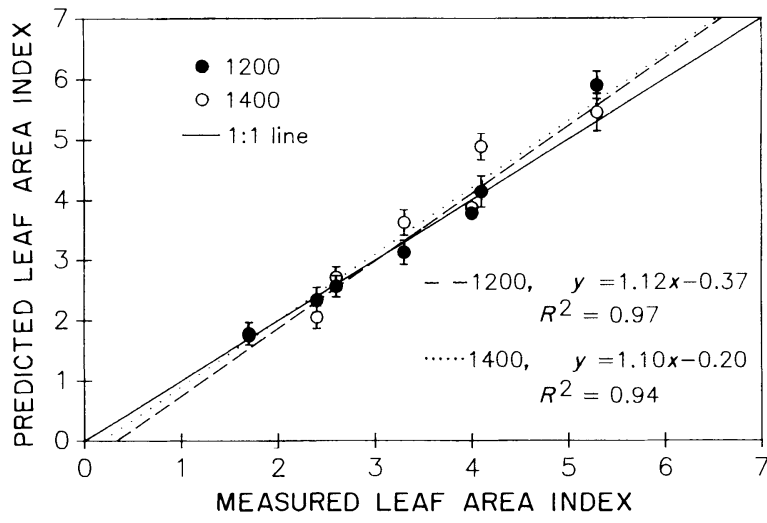

FIG. 2. Comparison of projected LAI measured using allometric equations with projected LAI predicted using the Beer-Lambert Law and light extinction coefficient $K=0.52$. The error bars represent \pm 1 standard error of the mean predicted LAI.

gesting that the ceptometer can be used to estimate LAI under a variety of stand structures and sun angles.

The effects of stand structure on the accuracy of the ceptometer-based predictions of LAI were assessed by plotting the relative estimation error for the 1200 transects as a function of sample size for each stand (Fig. 3). Estimation error was calculated using Eq. 2 and is expressed as a proportion of mean predicted LAI. Because $n$ and $t$ in Eq. 2 do not vary among stands, the coefficient of variation of predicted LAI controls the position of the curves on Fig. 3. For a given LAI, the coefficient of variation is controlled by the standard deviation of the predicted LAI, which is related to the variability in stand LAI or the distribution of foliage in the overstory. Therefore, stands with similar LAI but different distributions of leaf area will require different sampling intensities to obtain a given level of accuracy.

For example, the stands at Plains and Sorrel have roughly similar LAI, but the variation in LAI is lower at Plains, suggesting that Plains approaches a more random distribution of foliage. Fig. 3 shows that Plains requires fewer ceptometer samples than Sorrel to achieve a given level of accuracy. This is also true for Lubrecht and Rainy Lake, which have similar LAI. Again, the stand with lower variation in measured LAI, Lubrecht, approaches a more random distribution of foliage and requires fewer ceptometer samples to obtain a specified level of accuracy.

The effect of inherent sampling error on the applicability of this technique across a range of LAI is illustrated in Fig. 4. The standard deviation between the 10 repetitions of measured transmittance was the same for all three uniform light intensities (0.006), suggesting that the sampling error is independent of transmittance, as expected. However, application of the BeerLambert Law to predict LAI from measured transmittance has the effect of exponentially increasing the 
sampling error as LAI increases, so that estimates in stands with low LAI will have a proportionally smaller sampling error than in stands with high LAI. For example, transmittance sampled at a point under a uniform light source represented by LAI $=2$ could overor underestimate LAI by $>3 \%$ of true LAI in $5 \%$ of all samples. Transmittance sampled at a point under a uniform light source represented by LAI $=6$ could yield an estimate of LAI which differs from true LAI at the same level by $\pm 9 \%$.

The effect of the Beer-Lambert Law on sampling error can also be discovered by comparing the standard errors for each stand in Figs. 1 and 2. The error bars for Fig. 1 represent \pm 1 SE of mean transmittance and decrease with increasing LAI. However, when the BeerLambert Law is applied to estimate stand LAI, as in Fig. 2, the standard error of mean predicted LAI becomes proportionally larger at higher LAI. This potentially sets an upper limit of LAI to which this technique can successfully be applied.

\section{CONCLUSIONS}

The ceptometer can accurately sample transmittance across the range of LAIs $\left(1.7-5.3 \mathrm{~m}^{2} / \mathrm{m}^{2}\right)$, stand densities (450-4140 trees/ha), and effective incidence angles $\left(32^{\circ}-57^{\circ}\right)$ tested in this study. For these conifer stands, the ceptometer measurements of transmittance can be converted to accurate estimates of stand LAI using the Beer-Lambert Law and assuming an extinction coefficient $=0.52$.

The ability of this technique to estimate LAI is dependent upon stand structure. In stands such as Lubrecht, where overstory LAI approaches a random distribution, fewer samples are required to estimate stand LAI and sun angle influences are minimal. In stands where the distribution of LAI is less random and more clumped, such as Rainy Lake, more samples of trans-

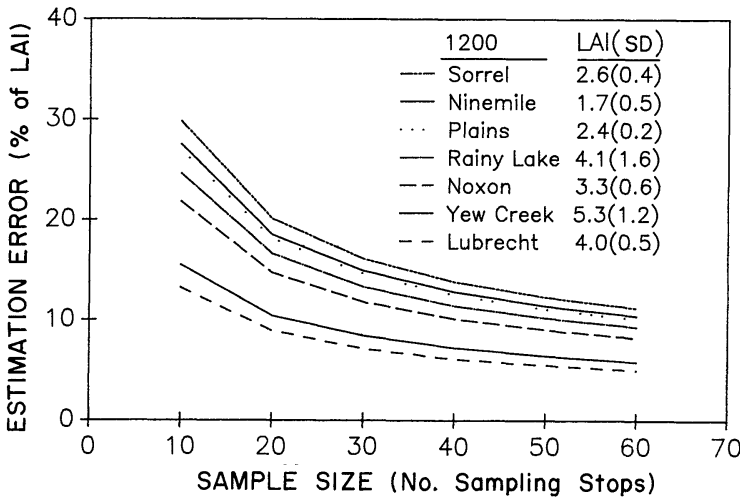

FIG. 3. The effect of sample size (sampling stops) on estimation error of the sampling technique in the seven stands for the 1200 transect. The estimation error on the $y$ axis is scaled as the proportion of predicted LAI at the $95 \%$ confidence level. The stands listed are in the same descending order as the curves.

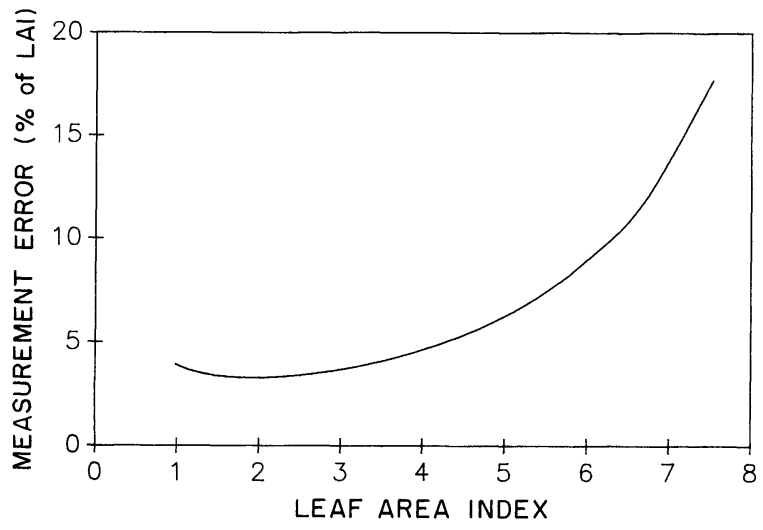

Fig. 4. The effect of the Beer-Lambert Law on ceptometer sampling error of transmittance at a point as it relates to predicted LAI. The measurement error becomes a larger percentage of LAI as LAI increases.

mittance are required to estimate LAI. Estimates of LAI in stands with clumped foliage will fluctuate with sun angle because the distribution of foliage in these stands strays from the assumptions implicit to the BeerLambert Law. The error inherent in the sampling technique could potentially limit the upward bound of the applicability of this technique.

Estimation of forest LAI over large areas is critical for interpreting satellite image products, such as the NDVI (normalized difference vegetation index) from the NOAA-9 AVHRR (Advanced Very High Resolution Radiometer) or LANDSAT-5 Thematic Mapper sensors (Running et al. 1986, Peterson et al. 1987, Running and Nemani 1988). Byrne et al. (1986) showed that estimates of forest productivity could be derived from the product of intercepted solar radiation integrated over time and an energy conversion efficiency term (mass/energy). The ceptometer could be used to provide measurements of intercepted solar radiation for this simple estimate of primary productivity.

\section{ACKNOWLEDGMENTS}

We wish to thank Dr. Gaylon Campbell and Jennifer Dungan for reviews of the original manuscript. Support for this work was provided with grants from NASA/Ames Research Center, Joint Research Interchange NCA2-138, and NASA Grant NAGW-955.

\section{LITERATURE CiTED}

Botkin, D. B., chair. 1986. Remote sensing of the biosphere. National Academy of Sciences, Report of the Committee on Planetary Biology. National Research Council, Washington, D.C., USA.

Byrne, G. F., J. J. Landsberg, and M. L. Benson. 1986. The relationship of above-ground dry matter accumulation by Pinus radiata to intercepted solar radiation and soil water status. Agricultural and Forest Meteorology 37:63-73.

Caldwell, M. M., H.-P. Meister, J. D. Tenhunen, and O. L Lange. 1986. Canopy structure, light microclimate and leaf gas exchange of Quercus coccifera $\mathrm{L}$. in a Portuguese macchia: measurements in different canopy layers and simulations with a canopy model. Trees 1(1):25-41. 
Decagon Devices. 1987. Sunfleck ceptometer users manual, Decagon Devices, Pullman, Washington, USA.

Gholz, H. L. 1982. Environmental limits on aboveground net primary production, leaf area, and biomass in vegetation zones of the Pacific Northwest. Ecology 63:469-481.

Grier, C. C., and S. W. Running. 1977. Leaf area of mature Northwestern coniferous forests: relation to site water balance. Ecology 58:893-899.

Hungerford, R. D. 1987. Estimation of foliage area in dense Montana lodgepole pine stands. Canadian Journal of Forest Research 17:320-324.

Jarvis, P. G., and J. W. Leverenz. 1983. Productivity of temperate, deciduous and evergreen forests. Pages 233-280 in O. L. Land, P. S. Nobel, C. B. Osmond, and H. Ziegler, editors. Ecosystem processes: mineral cycling, productivity and man's influence. Volume 12D. Physiological plant ecology: new series. Springer-Verlag, New York, New York, USA.

Landsberg, J. J. 1986. Physiological ecology of forest production. Academic Press, New York, New York, USA.

Lang, A. R. G. 1987. Simplified estimate of leaf area index from transmittance of the sun's beam. Agricultural and Forest Meteorology 41:179-186.

Lee, Richard. 1978. Forest microclimatology. Columbia University Press, New York, New York, USA.

Marshall, J. D., and R. H. Waring. 1986. Comparison of methods of estimating leaf-area index in old-growth Douglas-fir. Ecology 67:975-979.

McLeod, S. D., and S. W. Running. 1988. Comparing site quality indices and productivity in Ponderosa pine stands of western Montana. Canadian Journal of Forest Research 18:346-352.

McNaughton, K. G., and P. G. Jarvis. 1983. Predicting effects of vegetation changes on transpiration and evapo- ration. Pages $1-47$ in T. T. Kozlowski, editor. Water deficits and plant growth. Volume 7. Academic Press, London, England.

Norman, J. M., and P. G. Jarvis. 1975. Photosynthesis in Sitka spruce (Picea sitchensis (Bong.) Carr. V. Radiation penetration theory and a test case. Journal of Applied Ecology 12:839-878.

Pech, G. 1986. Mobile sampling of solar radiation under conifers. Agricultural and Forest Meteorology 37:15-28.

Peterson, D. L., M. A. Spanner, S. W. Running, and K. B. Teuber. 1987. Relationship of Thematic Mapper Simulator data to leaf area index of temperate coniferous forests. Remote Sensing of Environment 22:323-341.

Running, S. W., and R. R. Nemani. 1988. Relating seasonal patterns of the AVHRR vegetation index to simulated photosynthesis and transpiration of forests in different climates. Remote Sensing of Environment 24:347-367.

Running, S. W., D. L. Peterson, M. A. Spanner, and K. B. Teuber. 1986. Remote sensing of coniferous forest leaf area. Ecology 67:273-276.

Schroeder, P. E., B. McCandish, R. H. Waring, and D. A. Perry. 1982. The relationship of maximum canopy leaf area to forest growth in eastern Washington. Northwest Science 56:121-130.

Snell, J. A., and J. K. Brown. 1978. Comparison of tree biomass estimators-DBH and sapwood area. Forest Science 24:455-457.

Waring, R. H., P. E. Schroeder, and R. Oren. 1982. Application of the pipe model theory to predict canopy leaf area. Canadian Journal of Forest Research 12:556-560.

Wittwer, S., chair. 1983. Land related global habitability science issues. NASA Technical Memorandum Number 85841. National Aeronautics and Space Administration, Washington, D.C., USA. 